\title{
ONE MEAL A DAY
}

\section{An unexpected guest.}

\section{BY MILO JAMES FOWLER}

$\mathrm{F}$ irst thing Monday morning, Howard Schlange entered the living room of his one-bedroom apartment to find a well-dressed stranger sitting on the couch.

"Who are you?" Howard dropped back a step, his heart lurching against his chest.

"It is time for you to return," said the stranger, remaining seated. Only his head had turned, the hollow eyes in his pale face fixed upon Howard. "You have been here long enough."

Howard couldn't argue with that. Ever since construction on the freeway overpass had begun in earnest last month, the whole vibe of the neighbourhood had deteriorated. "You look like an undertaker."

"That does not change the situation."

"No, I guess not." Keeping a wary eye on the intruder, Howard edged to the bar that separated the living room from his kitchenette.

"Do not think to destroy me with a particle beam. It obviously did not work the last time."

"Obviously," Howard repeated, grasping his wallet and keys and holding them up. "I have an appointment."

"With destiny, yes."

"No, with a dentist." Howard licked his lips. His heart rate hadn't decelerated from high gear.

"Your grasp of this primitive language eludes me. How do you manage to hold that form?" A ripple coursed through the intruder's body as if there was a python coiled where his intestines should have been. "It is all I can do not to burst apart at the seams."

Howard blinked. "Listen, I don't have any cash -"

"You will not need cash - whatever it is — where we are going."

True enough; the insurance company would cover just about anything. "Wait. You're coming with me?"

"No. You are coming with me."

"That's kind of what I said." Howard stuffed the wallet into his back pocket and fiddled with the keys, jangling them against each other.

"What a dreadful sound!" The stranger's white, four-knuckled fingers flew to plug his ears. "Stop it at once!"

"Sorry." Howard dropped the keys into his pocket and glanced at $\rightarrow$ NATURE.COM

Follow Futures:

@ @NatureFutures

$f$ go.nature.com/mtoodm the front door, which showed no signs of forced entry. Neither did the balcony's

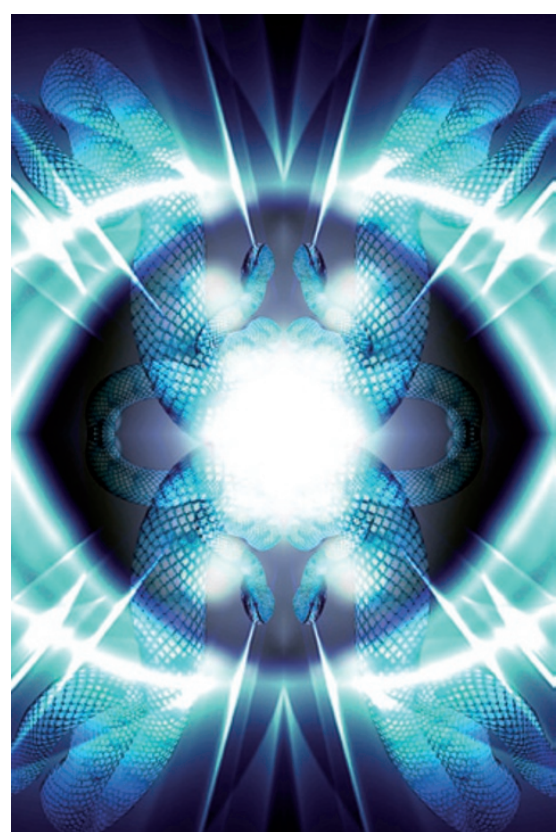

sliding door. Both were locked up, just the way he'd left them the night before. "How did you get in here exactly?"

"Much better." Mr Four Knuckles dropped his hands from his ears and stood suddenly, like a robot straightening itself. "Let us be on our way."

"Okay?" Howard moved towards the door.

"Where are you going?" the stranger snapped.

"The dentist. I told you -"

"There are far greater matters at stake, Prince Orionhart!"

"Orion-who?"

"Your father's kingdom is crumbling, Your Highness. The Crustaceoids lie at his very gates!" The impeccably dressed intruder came three steps forward, stomping his legs like stilts. "I realize we have had our differences in the past, that you never appreciated my meddling in your affairs, but you have to know that my only aim was to keep you safe from harm. Of course, as is the case with all youth, there comes a time when you desire to strike out on your own, leaving your doting caretakers behind, so I can understand why you attempted to kill me - "

"Huh?"

"Have you no memory of it at all?"

"It never happened - not with me, anyway." Howard tried to swallow but found a dry tongue in the way. "I think you've got me confused with somebody else. $\mathrm{Mr} \_$? waited for the stranger to fill in the blank.
Instead, the fellow started muttering to 㐫 himself: "I suppose it is possible that his brain chemistry could have undergone changes when he assumed the shape of one of these Earth creatures. I myself feel quite out of sorts. But it is highly unlikely that he would experience the sort of amnesia he appears to be exhibiting."

Howard almost smiled. "Oh, I get it. You think I'm an alien?" This was so cool all of a sudden!

The stranger scowled. "The oxygen must be affecting you -."

"You think I'm an alien prince? Holy cow!" Howard couldn't wipe the grin from his face. The weird visitor's skin began to contort as if underneath it was a nest of spider eggs that were all hatching at once. "You want to take me to your mothership?"

"I am not acquainted with the female, but if you are referring to the Cosmic Conveyor -"

Howard let out a whoop. "This is freakin' awesome!" All thoughts of his appointment vanished from his mind. He stood to attention, doing his best to contain himself. "All righty then. Take me to your leader."

The stranger blinked. "You are my leader."

"Right. So, take me back to wherever. Out there." He gestured vaguely at the ceiling.

The stranger's eyes squinted oddly as if the lower lids were attempting to devour his eyeballs whole. "I am beginning to have my doubts."

"I’m Prince Orionhead, ready to return to my homeworld. Beam me up!"

The stranger whipped a chrome pen from his breast pocket and pressed the tip with one of his long fingers. A white light enveloped him. "I believe I have made a mistake..."

"No mistake!" Howard charged into the light ... And ended up sprawled out on his couch, very much alone.

"Hey, what about me?" he shouted at the ceiling.

In the silence that followed, he heard only his stomach growling. How long had it been since he'd eaten last? After yesterday's mail arrived?

He looked down at his T-shirt and smirked at what appeared to be a pair of boa constrictors squirming inside his protruding belly. Shrugging, he headed out for his appointment.

Mailman had been a fine delicacy, but he couldn't wait to sample dentist.

Milo James Fowler is an English teacher by day and a speculative fictioneer by night. Find him at www.milo-inmediasres.blogspot.co.uk. 